Fecha de recepción: febrero 2013 Fecha de aceptación: julio 2013 Versión final: diciembre 2014

\section{Ámbito público, ámbito privado, ámbito independiente, fronteras desplazadas en el teatro de la Ciudad de Buenos Aires}

Rosalía Celentano *

\begin{abstract}
Resumen: El ámbito público, el ámbito privado y el ámbito independiente parecían mundos rígidos e insolubles. A partir de un determinado momento, se rompen los límites que los separan y comienzan a mezclarse. En el teatro público, aparecen caras de la tele y algunos espectáculos concebidos en ese ámbito migran a la cartelera independiente e incluso a la comercial. El teatro independiente comienza a atomizarse. El teatro comercial convoca a directores del teatro independiente o público a dirigir en su ámbito. Con estas incursiones se producen algunos cambios, en algunas salas.

Podemos decir que los ámbitos comenzaron a funcionar en red. Las fronteras se han desplazado según las necesidades y oportunidades de cada producción.

Los ámbitos sólo se diferencian por su financiamiento y sus objetivos.
\end{abstract}

Palabras claves: ámbito independiente - ámbito privado - ámbito publico - atomización del ámbito - financiamiento - la red - migración de ámbitos.

[Resúmenes en inglés y portugués en la página 117]

${ }^{(*)}$ Realizó estudios de teatro, dirección y de gestión cultural. Coordinadora de Producción Artística en el ámbito público. Realizó una Pasantía en Producción en Cirque du Soleil y en la Ecole National du Cirque en Montreal. Dicta seminarios de producción y administración cultural.

La globalización es un proceso a gran escala, que consiste en la creciente comunicación e interdependencia entre los distintos países del mundo, unificando sus mercados, sociedades y culturas, a través de una serie de transformaciones sociales, económicas y políticas que les dan un carácter global. Así, los modos de producción y de movimientos de capital se configuran a escala planetaria, mientras los gobiernos van perdiendo atribuciones ante lo que se ha denominado la sociedad en red (es.wikipedia.org)

Interno: Relativo a lo interior, aquello que está adentro. En física interno es lo microscópico. ${ }^{1}$ 
Si transcribiéramos esto a los distintos ámbitos en que se desarrolla un proyecto cultural o, más específicamente, el teatro de Buenos Aires, podemos decir que:

Globalización interna es un proceso a pequeña escala que consiste en la creciente comunicación e interdependencia entre los distintos ámbitos del mundo del teatro de la ciudad de Buenos Aires unificando sus sistemas de producción a través de una serie de transformaciones artísticas, económicas y comunicacionales.

La globalización es a menudo identificada como un proceso dinámico producido principalmente por las sociedades que viven bajo el capitalismo democrático o la democracia liberal y que han abierto sus puertas a la revolución informática, plegando a un nivel considerable de liberalización y democratización en su cultura política, en su ordenamiento jurídico y económico nacional, y en sus relaciones internacionales (es.wikipedia.org).

Plegar: Doblar una cosa sobre sí misma de manera que una parte se junte con la otra. Hacer pliegues o dobleces. Doblar sobre sí mismo un objeto articulado, para reducir su volumen y hacerlo más manejable. ${ }^{2}$

Nuevamente transcribimos al ámbito de la cultura de la ciudad de Buenos Aires y tenemos: La globalización interna es un proceso dinámico generado principalmente por los productores de los diferentes ámbitos en la búsqueda de la captación de público. Los caracteres que diferencian el ámbito público del privado se mezclarán provocando la ruptura de las membranas que separan sus formas, permitiendo que el contenido se vuelque de uno a otro ámbito como las células intercambian su plasma.

Las cosas no están quietas, se mueven, cambian, se trastocan, mutan, se entrelazan y nunca sucede una sola sino varias, muchas, a veces miles al mismo tiempo; eso es la vida. El teatro no está fuera de eso, entonces los factores que inciden en los cambios son varios al mismo tiempo, lo que no hace fácil su relato.

La velocidad con la que esos cambios han sucedido en un corto espacio de tiempo tampoco lo hace sencillo. Trataré de contarlo lo más claramente posible y a veces apelaré a casos para poder explicarlo.

Casi siempre pensamos que el disparador de nuestros cambios está afuera en el mundo. Primero las cosas suceden en Europa, EEUU, Japón, Canadá y luego aquí en nuestro país, pero no siempre es así.

Nuestro actual teatro independiente (Buenos Aires, 2011) tiene un formato y una dinámica que sólo sucede en Buenos Aires en particular, y en el país en general con variantes en sus características, pero sucede sólo en Argentina por innumerables factores, en los que ahora no nos vamos a detener. Este formato no tiene réplica en el mundo. 


\section{Otras veces las cosas suceden al mismo tiempo}

En 1996 yo era la productora artística y ejecutiva de una compañía de circo de escenario: La Trup, nuevo circo. Con mis dos socios viajamos a Montreal con una entrevista pactada con el Cirque du Soleil y otra con la Escuela Nacional de Circo de Montreal. Nuestra intención era quedarnos y aprender realizando una pasantía. Pero cada institución sólo nos había otorgado amablemente una sola entrevista, después de muchos meses de correspondencia y llamadas telefónicas. Llevamos fotos, carpetas y VHS de nuestros espectáculos. No existía el DVD, el VHS era lo más moderno en el mercado. Internet acababa de aparecer y como correo electrónico, no como fuente inagotable de información como lo conocemos hoy.

En nuestra entrevista en el Cirque en la sala de video del departamento de casting vemos junto a ellos nuestro último espectáculo, y al llegar a un número, una escena en particular, ellos paran la proyección, nos piden que los acompañemos a otro espacio del edificio (muy profesionales) y nos muestran en su espacio, destinado a la investigación para espectáculos futuros, que dos acróbatas ensayaban un número casi idéntico al nuestro, usando el mismo aparato, una rueda parecida a la de hamsters pero gigante, que nosotros habíamos inventado y mandado a hacer para nuestro espectáculo. "Nosotros no los copiamos a ustedes y ustedes no nos copiaron a nosotros" fueron sus palabras.

Aclarado esto volvimos a la oficina, terminamos de ver los videos, y por supuesto eso fue nuestro pasaporte a quedarnos una temporada a aprender.

Lo que quiero decir es que una misma idea puede ocurrírsele a dos personas en dos puntos muy distantes del mundo o una disciplina o estética evolucionar en el mismo sentido. Esta aclaración es porque algunas personas adjudican los cambios acontecidos en los últimos tiempos a modas provenientes de Broadway o Europa. Lo cual es cierto, muchas producciones comerciales se realizan en Buenos Aires porque han sido exitosas en esos lugares y se compra el formato pero ése también es otro tema.

Como se hace difícil separar minuciosamente los campos, para poder explicarlo mejor, vamos a definir cada ámbito como modelos estancos y como han sido hasta ahora.

\section{Ámbito público}

Objetivo: divulgación de la cultura. Hacer llegar a la mayor cantidad de público las distintas propuestas artísticas clásicas o contemporáneas. Concebido como un servicio público

- Elenco. En la mayoría de los teatros públicos hay elenco estable. Cuando no lo hay los actores que trabajan generalmente no pertenecen al mundo de la televisión o al teatro comercial. $^{3}$

- Remuneración. Los artistas cobran un sueldo fijo independientemente de la recaudación. La extensión del reparto no es considerada en la elección del repertorio porque justamente la relación costo/beneficio no es el motor de la producción. 
-Producción.Los decorados son desarmables. Estos teatros poseen talleres propios donde se realizan los vestuarios, las escenografías y la utilería. La mayor parte del personal artístico, técnico, administrativo y de gestión está mensualizado, lo que no hace posible calcular los costos de producción finales de cada obra. Los costos calculables son los sueldos de los actores y artistas contratados y las compras de materiales e insumos.

- Programación. Clásicos, “clásicos contemporáneos” y vanguardia. Convive más de una obra en cada sala. Se sostiene el concepto de optimización de espacio y horarios.

Se suele contemplar un espacio para propuestas de nuevas tendencias, dramaturgos jóvenes o debut de directores.

El teatro público 4 es reconocido como el teatro intelectual, culto, de texto o de vanguardia.

- Financiamiento. En su mayor parte dinero público, proveniente del presupuesto del Estado al que pertenece (Nacional, provincial o municipal), aprobado en la legislatura correspondiente al finalizar el año anterior a su ejecución. ${ }^{5}$ No hay sponsors, ni canjes, ni socios de inversión. ${ }^{6}$

- Precios. Los precios son populares, hay descuentos a jubilados y estudiantes, hay un día popular (mitad de precio).

Obligatorio: Ingreso sin cargo de discapacitados y, según la discapacidad, el de un acompañante.

- Comunicación. En las puertas, generalmente figura el elenco por orden alfabético y en el programa por orden de aparición, con fotos de alguna escena de la obra o a veces las fotos son posadas pero siempre en tamaño discreto, ya que lo más importante es la información. Casi no hay marquesinas y si las hay lo importante es el nombre de la obra, la foto es de una escena de la obra, el elenco lleva el mismo orden que el de las puertas y se vuelca casi toda la información. Cada institución tiene su estética, ciertos colores (generalmente las gamas de uno) y tipografías. Esto cambia según conceptos de dirección artística. Todas las obras que se anuncian tienen una línea estética, tal vez la diferencian los colores o algún detalle pero la estética es la misma.

La prensa pertenece a la institución con el mismo formato para todos los espectáculos. Figuración en la cartelera de los diarios por canje de entradas sin destacados.

- Publicidad. Casi no hay vía pública, ni avisos en los diarios, radios ni TV. ${ }^{7}$ 


\section{Ámbito privado}

\section{Objetivo: producción de espectáculos artísticos con recuperación de la inversión y obtención de ganancias}

- Elencos. Están formado por figuras generalmente pertenecientes a este ámbito desde siempre, otras provenientes de la televisión o del cine. Son siempre muy reconocidos por el público, muy mediáticas. Sus caras son tapas de revistas y de sección espectáculos de los diarios.

- Remuneración. Los artistas cobran según su capacidad para vender entradas, ya sea a través de su cachet fijo o a porcentaje del bordereaux, ese porcentaje varía según su cartel.

- Programación. Obras escritas especialmente para este ámbito. Pocas veces son llevados clásicos a este teatro. ${ }^{8}$ Generalmente se realiza una obra por sala con decorado fijo. Se apuesta a largas temporadas.

- Producción. Muchas veces la producción pertenece a la empresa que administra la sala, otras se trata de productores o empresas productoras que se asocian a un porcentaje con la sala, pero siempre existe un seguro diario de ingreso de taquilla para el empresario de sala. ${ }^{9}$ Las realizaciones se encargan en talleres privados presupuestadas previamente. No existe la flexibilidad de cambiar varias veces de idea en el proceso creativo. Cada cambio y cada minuto cuesta dinero. El personal mensualizado es el estipulado como indispensable por la Asociación Argentina de Empresarios Teatrales (AADET).

- Financiamiento. El capital pertenece a una persona física o empresa, se utiliza el sistema de sponsors, canjes, asociados o socios inversores.

- Precio de las localidades. Es alto y la variación se produce de acuerdo a la distancia de las butacas del proscenio. Las primeras más caras, y a medida que se acerca al fondo del teatro, el precio baja. No hay día popular, el descuento es opcional, según la empresa lo mismo que el ingreso sin cargo de los discapacitados.

- Puertas y marquesinas. Las marquesinas suelen tener fotos de grandes dimensiones de los actores para que el público reconozca sus caras. Se usan todos los colores. Cada obra tiene su estética. Si hay más de una sala en el mismo teatro no se conserva una estética en la comunicación. Los créditos (tamaño de letra, ubicación, cartel francés, etc.) se adjudican según importancia del personaje o según la trayectoria del actor o director. En letras grandes el nombre de la sala y el teléfono o dirección electrónica del lugar dónde se compran las entradas. Muchas veces, si el actor es una estrella, su nombre figura por encima del título de la obra. ${ }^{10}$ 
- Medios de comunicación y de promoción. Las campañas de prensa obligatorias son pactadas por contrato en duración y calidad.

- Publicidad. Los destacados en cartelera son obligatorios y los avisos en la sección de espectáculos o cartelera de los diarios pautados por contrato en cantidad, tamaño y medio, la vía pública también estipulada por contrato en cantidad y frecuencia, avisos en la radio y la TV. ${ }^{11}$

Toda esta descripción pertenece al Teatro privado empresarial o llamado comercial.

Hay otro teatro privado, llamado Independiente, que no tiene los mismos objetivos que el Teatro Empresarial, ya que no mide el éxito por el resultado de la taquilla.

\section{Teatro privado no comercial o independiente}

- Elencos. Si nos vamos muy atrás los elencos del teatro independiente eran los que ahora son los popes de la cultura en nuestra ciudad y podría decir de nuestro país. Sólo voy a dar un par de nombres de personas y salas: Alejandra Boero, María Rosa Gallo, Teatro del Pueblo, Fray Mocho, etc.

En los últimos años el teatro independiente ha sido protagonizado por los alumnos de las muchas escuelas de teatro que existen en Buenos Aires que, no teniendo dónde mostrar sus producciones, primero comienzan a mostrarlas en las salas independientes existentes y luego abren sus propias salas.

- Salas. Pocas sobrepasan las 100 localidades, generalmente con sillas, las menos tienen butacas, algunas poseen numeración en las ubicaciones, la mayoría no, la distribución del bordereaux se hace generalmente sólo a porcentaje. ${ }^{12}$ Escasas salas de este circuito tienen boletería electrónica.

- Producción. Las realizaciones están a cargo de pequeños talleres o a veces de la misma compañía. No hay personal mensualizado. Las formas son tantas como grupos o compañías existen.

- Financiamiento. Siempre de dinero propio aportado a cooperativa o en los últimos años obtenido de subsidios otorgados (Proteatro, INT, FNA, Iberescena, Fondo Metropolitano o instituciones internacionales).

- Remuneración. El reparto de la taquilla es a cooperativa. Algunas veces, generalmente cuando reciben subsidios, sólo se pagan los honorarios de los creativos o los servicios de los realizadores, con valores menores que los que se manejan en los otros ámbitos.

- Precio de las localidades. Es accesible, equiparado al del teatro público o menor. ${ }^{13}$ Descuentos a jubilados y estudiantes. Instalaron el 2X1. 
- Comunicación. Generalmente se realiza promoción con volantes, avisos en revistas de distribución gratuita. Actualmente a través de páginas de Internet o en Redes sociales. Generalmente no hay puertas ni marquesinas. Si las hay o si hay espacios para publicitar generalmente son todos los tamaños de carteles iguales o el orden de tamaño o importancia lo determina el horario que ocupan, si es central o no. Los créditos no son por orden de importancia de personaje o por trayectoria del actor o director. ${ }^{14}$ Pocas veces se puede hacer publicidad porque los números no lo permiten. Sólo algunos espectáculos pueden pagar un servicio de prensa.

- Programación. Conviven muchas obras en una misma sala. Cada una tiene generalmente 1 ó 2 funciones por semana. Los decorados deben ser fácilmente desmontables y ocupar poco espacio en el guardado.

\section{Mezclas y préstamos entre los diferentes ámbitos}

Estas características que los diferenciaban parecían rígidas e insolubles entre sí.

A partir de un determinado momento, casi junto con la caída del muro, estos mundos rompen la membrana que los separan y comienzan a mezclarse. ¿El huevo o la gallina? ¿Cuál primero? ¿Todos juntos? Empieza a verse en el teatro público alguna cara de la tele que hace muchos años atrás había estado cerca del teatro de texto y la ola de la fama la había arrastrado hacia otros mares. El teatro independiente que se había convertido en un teatro de grupos, comienza a atomizarse. Los grupos devienen en otros más pequeños con alguno de sus integrantes a la cabeza o los directores reúnen a pequeños grupos de actores concertados sólo para un espectáculo. Surgen nuevas salas de pequeño formato que albergan esas producciones. Algunas de esas experiencias toman una significativa importancia, comienzan a viajar y exportar sus producciones, abren sus propios espacios, crean sus propias escuelas. Las propuestas son tan interesantes que comienzan a convocar a actores ya consagrados en el mundo comercial o en la TV. Y como si esto no alcanzara empiezan a migrar espectáculos concebidos en el ámbito público a la cartelera independiente e incluso a la comercial manteniendo largas temporadas. Al mudarse de ámbito cambian el precio de las entradas y algunos recursos

Podemos decir que los ámbitos comienzan a funcionar en red.

\section{El teatro público se muda}

Mudanzas hubo muchas: La Madonnita con autoría y dirección de Mauricio Kartun: Estrena en 2003 en la Sala Cunill Cabanellas del Teatro San Martín, repite temporada en 2004 y en esos dos mismos años realiza temporadas en el Portón de Sánchez. Kartun repite la experiencia con El niño argentino, estrena en 2006 también en la Sala Cunill Cabanellas, se muda al Teatro Alvear en el mismo año y luego reestrena en el 2007 en el Teatro Regina y en el Teatro del Pueblo. 
Pero analicemos alguno.

En 2004 para la obra Nunca estuviste tan adorable, Javier Daulte invita a Mirta Busnelli junto a Carlos Portaluppi y a Luciano Cáceres a formar parte del Ciclo Biodrama, una producción del Complejo Teatral de Buenos Aires en el Teatro Sarmiento. Tiene un éxito increíble, realiza dos temporadas en ese teatro (2004 y 2005) y una en el Teatro de la Ribera (2005) en el barrio de La Boca. Al finalizarlas en 2006 se muda al Broadway 2 con cambios, porque los costos y posibilidades son distintos en cada caso.

En el Estado hay un socio que paga sin esperar respuesta financiera. El éxito o el fracaso se miden de manera diferente; en el teatro público no importa o no es lo más importante la ganancia, ni siquiera la recuperación de lo invertido.

En el teatro privado siempre se debe recuperar lo invertido y es primordial la ganancia. Cada minuto perdido vale dinero y cada error se paga. Nunca se puede saber el costo de las realizaciones en los teatros públicos porque los realizadores y la mayoría de los empleados que intervienen en la cadena de producción son un costo fijo.

La complejidad de una realización es subjetiva porque depende de cuánto trabajo o dinero tienen en ese momento.

En el mundo privado o de la vida real, como suelo llamarlo cuando estoy en el Estado y me refiero al privado, el costo es siempre el costo del mercado y es la sumatoria de todas las partes, aún cuando no se pague. Porque a veces en ese medio tampoco se pagan algunas cosas. Los canjes, los descuentos, existen, pero en el costo total se pone el precio real, y luego esos descuentos o canjes pasan a formar parte de la ganancia.

Hablo de los costos porque a la hora de cambiar de ámbito son el factor más importante. Si un espectáculo como Nunca estuviste tan adorable, con autoría y dirección de Javier Daulte, se va del teatro público al teatro privado, hay que evaluar los costos. La escenografía era una reconstrucción de una casa en la que transcurrían quince años con cambios de muebles y vestuario por época. En el Teatro Sarmiento y en La Ribera estaba fija porque era el único espectáculo que había, e incluso si había que desarmarla porque había otro espectáculo, este costo (significativo) lo absorbía la institución como productora, pero además por tener sus empleados mensualizados. La compañía, devenida en productora en el ámbito privado, debía pagar las horas de los maquinistas y utileros que se necesitaban para armar y desarmar todos los días porque en un teatro privado, para que un espectáculo sea el único y su escenografía sea fija, debe garantizar un nivel de éxito y venta de taquilla muy alto. El escenario del Broadway 2 era apaisado a diferencia de los dos anteriores por lo que hubo que reformular el decorado, el gran portón de fondo que daba paso a una escalera de mármol se transformó en una gran pared corrediza, las paredes de la casa estaban como extendidas y la misma cantidad de muebles distribuída de otra manera. Todo esto generó un gran aumento de los costos además de sumar prensa y publicidad, gastos que en el Estado son absorbidos por la institución. Se eliminó el telón de boca, que era un elemento importante de la puesta, porque el Broadway 2 no lo tenía y el que había en las salas anteriores era pequeño para la boca del nuevo escenario; comprar uno es un gasto impensable para una pequeña producción. ${ }^{15}$

De todos modos como espectáculo comercial tenía una ventaja, gran parte de su producción ya estaba resuelta, sueldos de ensayos, diseños, las realización del vestuario que cam- 
biaba en todos los personajes en cada escena y la mayor parte de la escenografía.

El cambio que sufre en lo administrativo es en su forma de reparto, todos pasan a cobrar a porcentaje de bordereaux y no con sueldos fijos mensuales, como en el ámbito público.

\section{Los contenidos se mezclan}

En estas mudanzas es donde comienzan a mezclarse los mundos porque se propone al teatro privado utilizar recursos del ámbito público o del teatro independiente para captar espectadores que no acudirían a un teatro comercial pero sí comprarían entradas para estos espectáculos siempre y cuando algo más que la obra y la propuesta se parezca al ámbito que frecuentan.

Ese algo más es lo que produce los cambios. Bajan los precios de las entradas en relación a la entrada estándar del teatro comercial. La publicidad tal como es concebida en este ámbito es inalcanzable para estas pequeñas producciones y es entonces cuando aparecen propuestas alternativas: avisos en revistas de distribución gratuita, blogs, tarjetas postales, la propuesta del 2X1, o de un día popular.

\section{El teatro público comienza a utilizar recursos del teatro privado}

Estas mezclas de lenguaje se producen también en el teatro público: cuando un actor famoso incursiona en él, algunas veces su nombre va por encima de la reglamentaria lista de orden alfabético o por orden de aparición. Nuevos medios comienzan a cubrir los espectáculos de los teatros públicos, noticias del teatro público comienzan a aparecer en revistas y programas mediáticos. Las obras del teatro público comienzan a circular por revistas o programas que sólo cubrían los chismes de la farándula. Las ternas de premios que antes consideraban sólo al teatro comercial empiezan a incluir producciones estatales.

\section{Comienza una nueva circulación de público}

En 2003 Romeo y Julieta, con dirección de Alicia Zanca y con Pablo Rago y Laura Novoa como protagonistas, se trabajó un tipo de retrato en las puertas y escaparates de la calle del Teatro Regio que se salía un poco del típico institucional. Las caras de esos actores y actrices en las puertas del teatro hicieron que se paren los vecinos con las bolsas del supermercado en la mano a mirar los carteles y acercarse a la boletería y preguntar cuándo eran las funciones. Esos mismos vecinos de las salas descentralizadas que antes no iban al teatro, pero ahora en el teatro de su barrio están los actores de la tele. Finalmente estamos utilizando recursos del teatro comercial para captar público en el teatro público. Yo he escuchado en la boletería del Teatro San Martín “deme cuatro para la de Rago". Un público que tal vez nunca habría visto Shakespeare; sin embargo el famoso acerca ese público y hasta lo captura para una próxima vez. 


\section{Otros recursos}

En 2000 trabajaba como coordinadora de producción en la Organización Teatral Presidente Alvear (OTPA) ${ }^{16}$. Al llegar a la mitad del año no teníamos presupuesto suficiente para programar, y teníamos la Sala Sarmiento terminando la temporada de La Excelsa de Juan Pablo Santilli con dirección de Oscar Barney Finn, obra con la que se reinauguró luego de ser reciclada completamente. Decidimos utilizar la gestión (herramienta del ámbito público) con algunas herramientas del teatro privado para programar la sala casi sin dinero, con los mejores resultados. Dos años antes el Teatro San Martín había estrenado La fabulosa historia de los inolvidables Marrapodi de Los Macocos, repitiendo temporada en 1999. Decidimos pedir al TGSM la producción prestada ${ }^{17}$, hacer una coproducción entre la OTPA y la Banda de Teatro Los Macocos como productora ${ }^{18}$ y asociar a esa coproducción una empresa de publicidad que aportaba una campaña de vía pública ${ }^{19}$ también a porcentaje. De esta manera, utilizando un sistema mixto se pudo sortear la crisis. Luego resultó que, en el medio de estas negociaciones, la OTPA y el TGSM se fusionaron, con lo cual ya no había convenio entre las dos instituciones. En la OTPA ya habíamos usado algunas estrategias privadas obligados por el escaso presupuesto con que contábamos para la cantidad de salas que reunía la organización. Hicimos algunos convenios con empresas como Metrovías, Personal, Trapiche, Diners Club International, SOS Emergencias Médicas, Netizen, Vitamina, C\&A y otros en calidad de sponsors o canjes por publicidad.

En la actualidad el Complejo Teatral de Buenos Aires tiene como sponsor principal al Banco Ciudad y convenios con la fundación YPF, la UP, y las empresas Avon y Movistar entre otras. Y en temporadas anteriores con otras empresas.

También realiza coproducciones con empresas productoras públicas y privadas, nacionales e internacionales ${ }^{20}$.

\section{Todo cambia}

El teatro independiente comienza a utilizar recursos del teatro comercial. Empiezan a ver su obra como producto. Las compañías comienzan a pensar con cabeza marketinera: instalan marca, se ponen nombre, tienen logo, contratan prensa, con la aparición de Internet tienen blog o página. Empiezan a imprimir piezas gráficas, programas, volantes y hasta surge la posibilidad de hacer vía pública en pequeño formato, herramienta publicitaria antes sólo patrimonio del teatro comercial y muy esporádicamente del teatro público. La modalidad de 1 ó 2 funciones por semana comienza a ser exitosa, las salas se llenan y las obras se mantienen por muchos meses y hasta más de un año en cartel. Las ideas de éxito y fama circulan en el Teatro llamado Independiente. Se recuperan las inversiones. Aparecen los subsidios. Se deja de poner plata para ir a trabajar y se conoce el concepto de rentabilidad; las compañías se autogestionan copiando a pequeña escala el modelo comercial. Se consiguen canjes o sponsors que hacen posibles algunas producciones. Antes el teatro independiente tenía un precio de las localidades casi siempre menor que el del teatro público con el que se sentía emparentado, pero sin la capacidad de producción del mismo. En cuanto aparecen las nuevas formas de financiamiento, el nivel de producción 
artística comienza a crecer y entonces, pensando en la rentabilidad, suben los precios de las entradas equiparándose a las del teatro público y en algunos casos están por encima de ese valor. Las salas que albergan estas producciones también mutan: mejoran sus equipamientos técnicos, sus butacas, construyen gradas para que las sillas ya no queden a ras del piso, instalan aire frío-calor y hasta boleterías electrónicas. Algunas salas comienzan a cobrar seguros, antes patrimonio del teatro comercial. Se destinan espacios especiales para que cada producción haga su comunicación, fotos, críticas y hasta piezas gráficas, todo con cierto criterio estético. Varias salas, junto con las compañías, comienzan a idear un sistema de consorcio para publicar en revistas la programación mensual o incluso para pagar campañas de vía pública. Algunas de estas producciones suben la apuesta y agregan al sistema de producción un socio inversionista que a veces está dentro de la compañía, y otras fuera, y puede ser una persona física o una empresa. En algunas producciones se suman actores de larga trayectoria teatral o algunos de la TV, lo que intensifica el uso de recursos del teatro comercial: diseño, publicidad, marketing, prensa, notas.

Daniel Veronese, que tiene su propio espacio, deja de trabajar en él y sale a otras salas con versiones de clásicos y "clásicos contemporáneos", mezclando en sus puestas un actor consagrado del teatro, como Osvaldo Bonet, con jóvenes actores y con otros de larga trayectoria en el teatro público y/ o en el independiente y hasta alguno que proviene de la televisión. Estas propuestas cobran tanto éxito que se exportan. José María Muscari es otro que incursiona en esas mezclas con éxito.

Claudio Tolcachir, sin agregar famosos a sus producciones, comienza con sus alumnos a generar gran afluencia de público, y las localidades se agotan por varias temporadas. También consigue exportar su teatro. El fenómeno del teatro independiente viajando por el mundo se repite con muchos otros directores.

\section{Independiente / Público / Independiente}

Julio Chávez entrenaba actores en su estudio, Rancho fue hecha con algunos de esos actores y formó parte de una propuesta de donde nacieron varias obras suyas.

Cuando la estaba terminando en su estudio pensó que la sala del subsuelo del Teatro San Martín sería un espacio posible donde la obra pudiese verse.

Llamó a Kive Staiff y lo invitó a verla y le propuso hacerla en la Sala Cunill Cabanellas. La propuesta fue aceptada, se completó la producción artística y realizó dos temporadas con gran éxito. Al terminar esas temporadas el proyecto se mudó al Camarín de las Musas ${ }^{21}$, espacio que permitió que el cuarto (la escenografía era la reconstrucción de un cuarto de un departamento de Barrio Norte) sea montado con rapidez. En el montaje se resignó el piso que tanto trabajo y beneficios diera en el San Martín, pero salía muy caro ponerlo y quitarlo. La inversión estuvo orientada a la prensa y publicidad, gastos del ámbito comercial y que en el ámbito público absorbe la institución, pero como la obra empezó a generar una media de público estable pronto cambiaron la inversión a mantener la calidad del programa, imprimir postales, hacer buenas fotos volviendo a las acciones típicas del teatro independiente 22 . 


\section{Límites imprecisos}

Una producción claramente montada entre el mundo comercial y el independiente fue Sucio, con dirección de Ana Frenkel y Mariano Pensotti. Este espectáculo se estrenó en el Konex en 2007 con escenografía fija. Desde un principio la reconstrucción de un lavadero automático con techo, piso, lavarropas que giraban, micrófonos inalámbricos y una planta lumínica muy importante, la diferenciaba de una producción independiente simple y la acercaban más al ámbito comercial. En 2008 en la mudanza a la sala de El Cubo se presentan decisiones de producción. Al convivir en la misma sala con otros espectáculos, debió resignar el techo para acortar tiempos de armado y desarme, además de no contar con espacio suficiente para guardarlo. El espectáculo realizó temporada en 2008 y 2009 en esta sala. Se trabajó mucho la comunicación y la publicidad. Todas las medidas que se tomaron eran del teatro comercial, pero repensadas a la escala del proyecto. Vía pública, canjes, sponsors, notas, fiestas, prensa de cada una de las acciones. La reinversión es un recurso del teatro comercial. En este espectáculo se trabajó con ese concepto, reinvirtiendo permanentemente lo ingresado por taquilla en publicidad y mantenimiento de la calidad artística del proyecto.

Otra producción de límites imprecisos fue La luna de Oriente de Flavio Dumaine. Una obra para toda la familia que mezclaba la acrobacia, el teatro negro y la animación. Una producción independiente pero con recursos comerciales incluido el merchandising. En 2009 (gripe A mediante) este espectáculo con proyecciones de animación sobre negro, con la reconstrucción simple pero esmerada de un mundo oriental y mágico, con una fuerte apuesta en vía pública, campañas de radio y spots en televisión por cable, se diferenciaba de las propuestas habituales del teatro independiente. El armado de la caja negra, en una sala dónde convivían tres y cuatro espectáculos por día ${ }^{23}$, según si eran día de semana o fin de semana, requirió además de ensayos de armado y desarme, de un esquema de superposición de horas de trabajo de los técnicos de cada espectáculo para realizar los armados de cada uno de ellos. ${ }^{24}$

\section{Todo para vender}

El Teatro comercial convoca a directores del teatro independiente o público a dirigir en su ámbito. Así Javier Daulte, Claudio Tolcachir, Daniel Veronese, Rubén Szuchmacher, José María Muscari, Luciano Suardi, dirigen con éxito en teatros privados. Con estas incursiones se producen algunos cambios, en algunas salas. No sólo su convocatoria es la novedad sino también en algunos casos se eligen textos casi patrimonio del teatro público o del viejo teatro independiente. El público que frecuenta estos espectáculos no es el mismo que asiste al teatro comercial y la mayoría no está acostumbrada a pagar los precios del teatro privado. Los empresarios privados reacios históricamente a los precios populares y a las ofertas de 2x1 (herramientas del mundo independiente), a publicidad no comercial $\mathrm{y}$ a invitaciones masivas poco a poco empiezan a ceder a esas propuestas seducido por los resultados obtenidos. Inevitablemente hay un aumento de espectadores, atraídos por los 
títulos o por los directores; por la diferencia. Los nuevos directores convocaron a actores que no eran caras de la televisión o consagrados para personajes importantes. El público los aprobó y la televisión comenzó también a convocarlos.

Paralelamente otro fenómeno que tal vez sea atribuible a Suar, la aparición en la TV de muchos actores de teatro. Esto hace que al volverse más conocidos para el público general, se los convoque en teatro comercial. Y así se genera un circuito que se retroalimenta. Actualmente en casi todos los canales hay tiras o unitarios protagonizados por una mezcla de actores que proviene de la tele misma, del teatro público e independiente y del teatro comercial.

\section{Instituciones intermedias}

Hay instituciones como Ciudad cultural Konex ${ }^{25}$, el Centro Cultural de la Cooperación, Fundación Telefónica y otras que desarrollan proyectos artísticos y que tienen funcionamientos intermedios o fronterizos.

Son instituciones privadas pero a veces se inclinan a funcionar como si fuesen públicas y otras como lo que son: privadas. Si bien son parecidas son diferentes entre sí.

Analicemos las dos que se dedican al teatro: Konex y CCC.

Coincidencias: ambas a veces funcionan como productores de sus propios proyectos y otras veces reciben a los mismos como empresarios de sala; ambas reciben obras del ámbito independiente. ${ }^{26}$

Diferencias: Konex, en sus salas de mayor capacidad, alberga proyectos de corte comercial pero que necesitan espacios e inversiones más pequeños que los que requieren los teatros privados de ese circuito. Posee muchas salas y todas se manejan de forma diferente pero en su comunicación y en sus contratos es claramente cercana al modelo comercial. ${ }^{27} \mathrm{El} \mathrm{CCC}$ incorpora en su programación espectáculos alternativos al modelo hegemónico y en sus contratos toma claramente el modelo público sin asumir el compromiso de los sueldos de los artistas. ${ }^{28}$

\section{Lo importante}

Los límites están corridos, los contenidos transportados, los recursos mezclados; el resultado: muchas opciones

Llegamos al final, con todas estas transformaciones, a un escenario con paredes imprecisas. Las fronteras se desplazaron según las necesidades y oportunidades de cada producción.

Los ámbitos han dejado de diferenciarse por sus actores, creativos, directores, autores o sus recursos de comunicación. Sólo los diferencian su financiamiento y sus objetivos.

Y hablando de objetivos, el objetivo final de todo proyecto teatral, es su confrontación con el público; todos estos cambios sólo se han producido en pos de la captación de ese público. 


\section{Notas}

1. Recopilación de significados en el diccionario.

2. Significados del diccionario.

3. Esto se ha modificado. Ver El teatro público se muda y Los contenidos se mezclan.

4. Como responden a las políticas culturales de los gobiernos del momento, se los suele llamar "teatros oficiales".

5. El resto del presupuesto se completa desde hace unos años por el ingreso de boletería del período anterior. Lo que ha incentivado a que se piense más en la recaudación.

6. Esto también se ha modificado. Ver Otros recursos.

7. En algunos períodos y determinado por una decisión política de los gobiernos del momento existen campañas de vía pública para estos teatros o canjes con diarios o alguna empresa o institución oficia de sponsor.

8. Esto se ha modificado en los últimos años. Si revisamos la cartelera encontramos Un tranvía llamado deseo, de Tennessee Williams en el Teatro Apolo, La muerte de un viajante, de Arthur Miller en el Complejo La Plaza, Todos eran mis hijos, de Arthur Miller en el Teatro Apolo, La vuelta al hogar, de Harold Pinter en el Multiteatro, etc. Todas de autores casi patrimonio exclusivo del Teatro público.

9. Este formato de seguro de sala antes era patrimonio de las salas comerciales. Ha cambiado en la actualidad.

10. Esto también ha sido patrimonio del teatro comercial. Hoy ha cambiado.

11. Algunos de estos requerimientos han variado por los cambios que se detallan más adelante.

12. En la actualidad este sistema se ha diversificado. Las salas que poseen subsidios del INT o de Proteatro no cobran seguro de sala. Las salas que no poseen esos subsidios cobran un seguro de sala que varía según la sala, su ubicación y su infraestructura. Entonces el acuerdo de porcentajes sólo funciona cuando el porcentaje supera el seguro.

13. Este recurso ha cambiado al modificarse el sistema de producción. Ver Todo cambia

14. La excepción se produce cuando hay algún actor, director o actor que pertenece a otro de los ámbitos entonces se lo destaca para captar más público y publicidad.

15. Todos estos datos fueron cotejados con Javier Daulte.

16. Hasta 2000 la OTPA estaba compuesta por el Teatro Presidente Alvear, el Teatro Regio, El Teatro Sarmiento, el Teatro de La Ribera y el Anfiteatro de Alberdi, y pertenecía a la Municipalidad de Buenos Aires, al igual que el Teatro Municipal General San Martín.

A partir de septiembre de 2000 se unifican en el Complejo Teatral de la Ciudad de Buenos Aires (CTBA), perdiendo el Anfiteatro que quedó en manos de la Dirección General de Música(DGM)

17. Ahorrando así los costos de realización escenográfica y de vestuario.

18. Así la productora recibía un porcentaje del bordereaux y el teatro no se veía obligado a pagar los sueldos mensuales, cosa que la falta de presupuesto nos impedía.

19. Con esto teníamos un doble beneficio: la campaña de la comunicación de la obra y la de la reapertura de la sala. 
20. Ejemplos de la programación 2010/2011: La vida es sueño, El pasado es un animal grotesco, Hamlet, Hilvanando cielos, entre otros.

21. El Camarín de las Musas es un espacio que tiene varias salas. Es reconocido como del ámbito independiente, pero algunas de sus salas siempre tuvieron condiciones de teatro comercial, como el pago de seguro.

22. Información suministrada por Julio Chávez.

23. Uno tenía caja y piso blanco, otro piso negro pero otras paredes y La Luna de Oriente piso y paredes negras, pero además debían taparse todos los posibles ingresos de luz para lograr la caja para teatro negro.

24. Sucio y La Luna de Oriente fueron producciones de Tónicas.

25. Conocida como el Konex

26. El Konex en sus salas pequeñas y a veces en las grandes y el CCC en todas sus salas.

27. Ver Ámbito Privado. Comunicación. Publicidad.

28. Ver Ámbito Público. Precios. Comunicación. Publicidad. Su personal técnico y administrativo está mensualizado.

Summary: The public sector, the private sector and the independent sector seemed rigid and insoluble worlds. From a certain point, the boundaries between them were broken and began to mix. In public theater, TV faces shows-up and some shows designed in this area migrate to the independent billboard and even to the commercial one. The independent theater began to atomize. Commercial theater convenes independent and public theater directors to direct in its field. Due to these changes we can say that the field began networking. The boundaries have shifted according to the needs and opportunities of each production. The areas differ only because of funding and its objectives.

Keywords: area atomization - environment migration - funding - independent field - network - private sector - public sector.

Resumo: No âmbito público, o âmbito independente pareciam mundos rígidos e insolúveis. A partir de um determinado momento, se quebram os limites que os separam e começam a misturar-se. No teatro público, aparecem caras da TV e alguns espetáculos concebidos neste âmbito migram ao âmbito do teatro independente e ao comercial. O teatro independente começa a fragmentar-se. O teatro comercial convoca diretores do teatro independente ou público para dirigir no seu âmbito. A partir destas incursões se produzem, em algumas salas, algumas mudanças. Pode se dizer que os âmbitos começaram a funcionar em rede. As fronteiras se transladaram segundo as necessidades e oportunidades de cada produção. Os âmbitos se diferenciam por seu financiamento e seus objetivos.

Palavras chave: âmbito independente - âmbito privado - âmbito público - fragmentação do âmbito - financiamento - a rede - migração de âmbitos. 